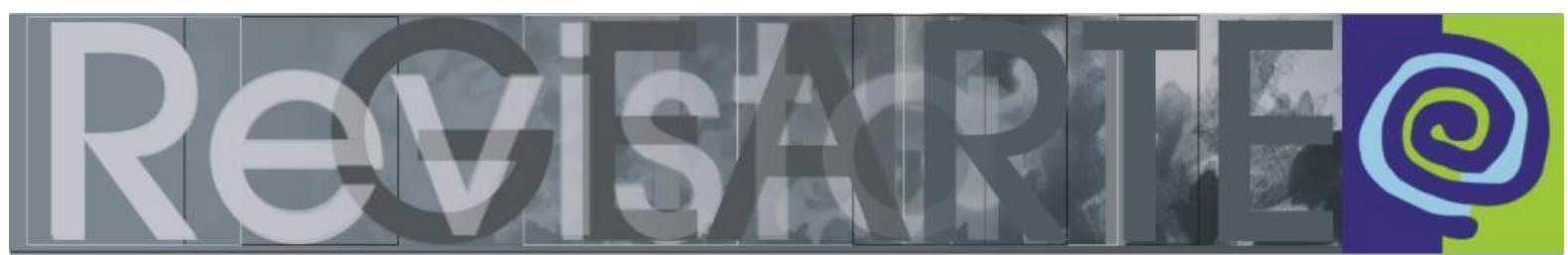

e-ISSN 2357-9854

\title{
Das Três Vertentes: instauração de um tripé metodológico para processos de criação artística
}

\author{
Marcilene Ladeira (Universidade Federal da Bahia — UFBA, Salvador/BA, Brasil)
}

\begin{abstract}
RESUMO - Das Três Vertentes: instauração de um tripé metodológico para processos de criação artística - O presente artigo, destaca a experiência visual como paradigma no processo de pensamento da história da arte, que confluirá, na contemporaneidade, em uma autoconsciência do próprio artista, em que ele mesmo passará a fazer filosofia a partir de sua obra. Desse viés, propôs-se a criação de um tripé metodológico, denominado Método das três Vertentes, aplicado ao ensino das Poéticas Visuais em meio universitário, sendo consolidado a partir de um design que elucida a relação "objeto-sujeito-meio". Para esse fim, explorou-se a interação entre teorias que envolvem o fazer artístico, o conceito de conhecimento e a ciência física, no que diz respeito ao entendimento de campo gravitacional e linhas de força.
\end{abstract}

PALAVRAS-CHAVE

Pesquisa em poéticas visuais. Cultura visual. Metodologia de ensino.

ABSTRACT - The Three Strands: establishment of a methodological tripod for artistic creation process - The present article, highlights the visual experience as a paradigm in the research process of the history of art, which will converge in contemporary times into a self-consciousness of the artist himself, in which he himself begins to make a philosophy from his own work. From this point, we proposed the creation of a methodological tripod, called the Three strands methods, applied to the teaching of Visual Poetics in a university environment, being consolidated from a design that elucidates the relation "object-subject-means". To this end, explore an interaction between theories that involve artistic doing, the concept of knowledge and a physical science, with regard to the understanding of gravitational field and lines of force.

KEYWORDS

Research in visual poetics. Visual culture. Teaching methodology.

$\mathrm{E}$, agora, de repente, havia uma obra de arte que, curiosamente, não se poderia distinguir de uma caixa de embalagens. Contudo, isto significava que reconhecer algo como uma obra de arte era uma transação perceptiva mais complexa do que qualquer um poderia ter suposto antes (DANTO, 2013, p. 88).

O trecho acima se refere ao episódio artístico da Brillo Box de Andy Warhol ocorrido em 1964; no qual, a partir do encontro do filósofo e crítico de arte Arthur Coleman Danto (1924-2013) com a obra em questão, declara perceber que a natureza da arte precisava de novas formulações: "de repente, pareceu-me que a definição de arte tornara-se urgente", "elas não dão mais conta para o que vejo diante de meus próprios olhos". Como esta caixa, tão fac-símile as de embalar "Brillo14" presente nas prateleiras dos supermercados poderia estar exposta numa galeria como a Stable Gallery? - questiona Danto. 
Virginia Aita (2006), pesquisadora acerca do pensamento do autor, explica que acabou por se tornar protagonista das mais efervescentes e polêmicas teorias na arena da arte contemporânea. O fim da arte é a ideia que amarrará as novas colocações introduzidas pelo americano, as quais, com efeito, nada mais são do que o fim de uma grande narrativa evolutiva (ou percurso histórico) da arte e que confluirá em uma autoconsciência do próprio artista, na qual ele mesmo passará a fazer filosofia a partir de sua obra. Nessas condições, Danto se opõe ao alemão Friedrich Hegel (1770-1831), conforme explica:

\begin{abstract}
[Hegel] viu que era possível pensar pela matéria (in the medium of matter) e sua concepção de arte reconhece isso tal e qual. Porém, ele acreditava que isto limitava a arte de uma maneira desfigurante, uma vez que na sua natureza, a arte tinha que pensar pela matéria. Sua filosofia da arte era refém da sua metafísica. Eu [Arthur Danto], ao contrário, acredito que a arte tem sido capaz, através da sua evolução, de nos levar ao coração de sua filosofia (DANTO, 2013, p. 86, grifo meu).
\end{abstract}

Não obstante, Danto trilhou esse caminho e, a partir da "visualidade artística", introduziu suas célebres ideias. Jovem, e ainda em início de carreira, primeiro como pintor (1950), depois como crítico (1984), dedicava-se à arte e à filosofia simultaneamente - "era como viver duas vidas paralelas". "Eu fiz algumas exposições e pintava como Franz Kline, só que figurativamente" - lembra Arthur Coleman Danto. (Cf. VINICIUS, 2005).

Por essa via de entendimento no fazer arte na contemporaneidade penso nas "linhas de força" que agem no processo de criação artística. Mas como assim? O que quero dizer com isso? Refiro-me ao que Cecília Salles menciona em seu livro "Redes de Criação: construção da obra de arte" (2006) - duologia iniciada em uma publicação anterior: "Gesto Inacabado" (1998); estudos bastante fundamentados no que diz respeito às interconexões existentes no percurso criativo. Conforme a pesquisadora verifica-se:

[...] o desenvolvimento do processo [de criação] vai levando a determinadas tomadas de decisão que propiciam a formação de linhas de força. Essas passam a sustentar as obras em construção e balizam, de algum modo, as avaliações do artista. Os percursos apresentam tendências que podem ser observadas como atratores, que funcionam como uma espécie de campo gravitacional e indicam a possibilidade que determinados eventos ocorrerem (SALLES, 2006, p.16, grifo meu). 
Mas o que seriam essas linhas de força e campo gravitacional, presentes na criação artística, descrito por Salles? É o que procuro entender neste estudo, pois me sinto enleada por elas durante meu próprio fazer. Logo, como Danto, parto em busca de compreensão - o pesquisador precisa desse instinto investigativo.

Ao deslocar-me para a ciência física - procedimento descomplicado devido à proximidade com a área - rememoro a atuação em um Centro de Ciências, onde participei de Projetos de pesquisa na interface "Arte e Ciência", bem como em processos de divulgação científica. Com isso, prontamente, vem-me a clássica imagem de Isaac Newton (1643-1727), lendo seu livro debaixo de uma macieira e, repentinamente, uma maçã cai sobre sua cabeça. Conforme consta, foi esse o fenômeno que the deu propulsão para avançar em conceitos da gravidade. Em explicações desta, trazidos pela ciência física, campo gravitacional e linhas de força têm-se existência e propriedades concretas, podendo até se chegar a cálculos matemáticos de seus atributos, como quantidade de energia e direção. Nessas condições, é próprio dizer que ao redor de "todo" corpo com massa existe uma região no espaço, contendo uma força que, embora seja invisível é real - é o que se chama de campo gravitacional. Em outras palavras, ter-se-ia: região de perturbação gravitacional que um corpo gera ao seu redor e que, por sua vez, é representado por um conjunto de linhas denominadas linhas de força do campo gravitacional. "Assombramos como a natureza foi capaz de seguir com tamanha abrangência e generalidade um princípio tão elegantemente simples [como este]" - é o que está expresso no livro "Feynman Lectures on Physics" (2009, p. 68).

Em vista disso e, ao considerar que a obra em construção se refere ao objeto que se pesquisa, sendo, pois, uma coisa concreta - passamos à aplicação da teoria descrita. Assim, elaboro, então, o seguinte esquema visual: 


\section{Figura 1 - Objeto de pesquisa e o possível campo gravitacional que o envolve}

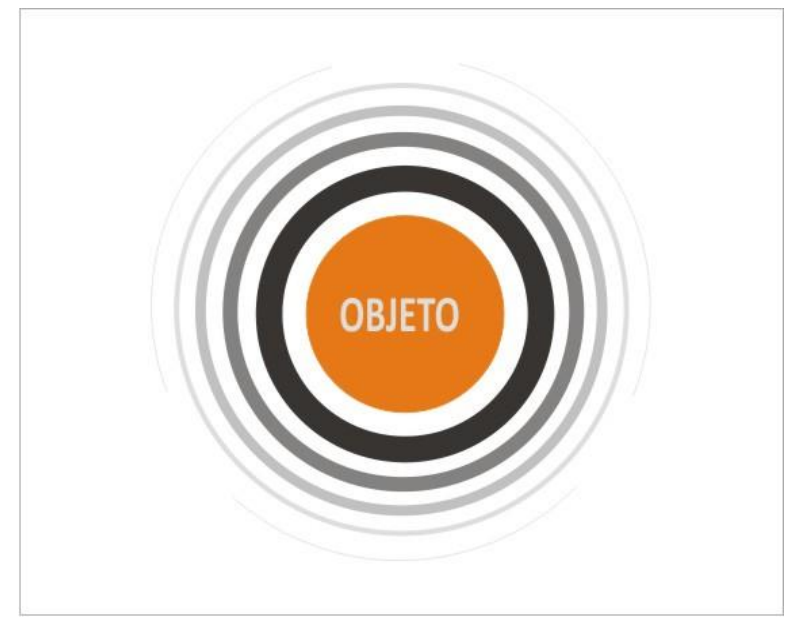

Fonte: Representação hipotética elaborada pela autora (2014/2015).

$\mathrm{Na}$ figura, o campo gravitacional está representado em linhas de força circulares que decrescem à medida que distanciam do corpo. Por meio desse campo, quaisquer "objetos" que se aproximam ficam sujeitos a uma força atrativa, mesmo que não estejam em contato direto. Por isso, entende-se como ação à distância proferida nos avanços de pesquisa realizados por Isaac Newton. Tais questões, simplesmente, não param, pois se evidencia, também, que o campo gravitacional (gravidade da Terra ou Lei da Gravitação Universal) é análogo ao campo elétrico (cargas elétricas: elétrons, prótons ou íons) e ao campo magnético (imã). O que os diferencia são suas constantes $^{1}$ e o fato de que a gravidade é sempre atrativa, enquanto a eletricidade e o magnetismo podem ser atrativos ou repulsivos. Nesse estudo, irá se considerar, para o dado objeto (que se pesquisa), os dois pólos (força atrativa e repulsiva). $\mathrm{Na}$ Figura seguinte, ver-se-á essa representação:

1 Pode ser comparada com uma constante matemática, que é um valor numérico fixo, mas não envolve diretamente qualquer medida física. Ex.: a constante gravitacional $G$, campo elétrico $\vec{E}$, campo magnético, $\vec{B}$. 


\section{Figura 2 - Forças de atração e repulsão sobre o objeto que se pesquisa}

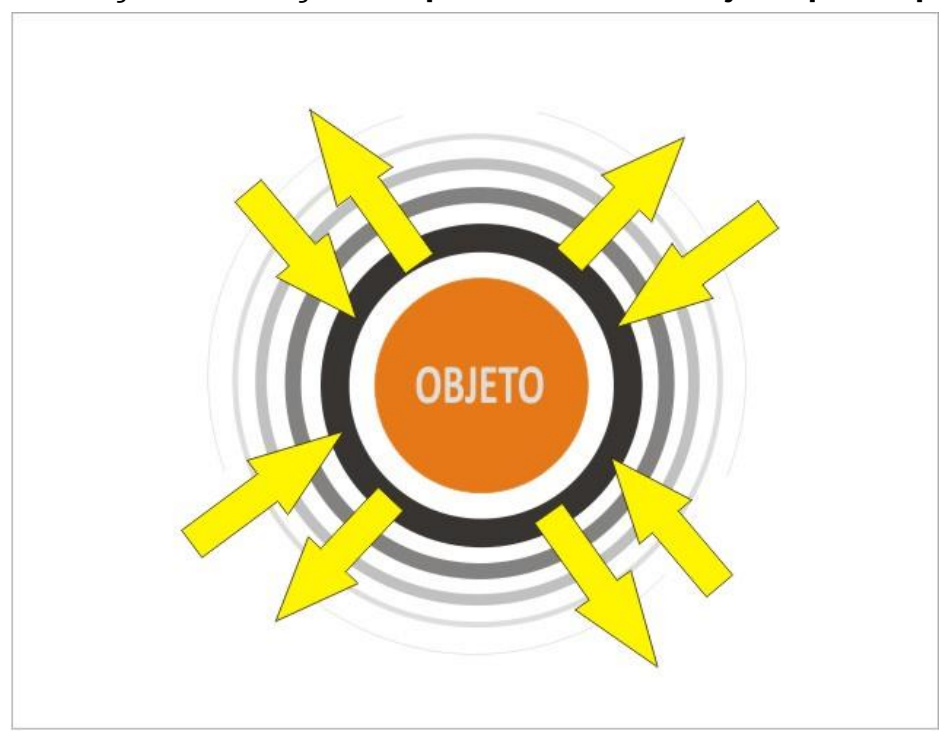

Fonte: Representação hipotética elaborada pela autora (2014/2015).

As setas amarelas indicam, portanto, a direção e o sentido das forças que incidem sobre o objeto de pesquisa (atração ou repulsão) que sujeitará quaisquer ações - teóricas ou práticas - colocadas à vista do que se busca. Cabe a nós, sujeitos cognoscentes, estabelecer os devidos ligamentos ou descartes quando necessário.

Em uma pesquisa, além do objeto há o sujeito-pesquisador. Em autores voltados para a metodologia da pesquisa científica, como Isaias Santos Neto, confirmamos que o conceito de "conhecimento" se processa justamente desta relação - "relação entre sujeito e objeto".

Assim, profere Santos Neto: "só podemos ser sujeitos se de algum objeto, da mesma maneira que objetos somente existem se para algum sujeito." (SANTOS NETO, 2004, p. 22, grifo do original). E o autor continua:

\footnotetext{
O conceito sujeito (sub+jactus) indica que algo exterior é "lançado" para dentro do observador, como registro na consciência de alguma experiência [...]. Enquanto isso ocorre com o sujeito, o conceito objeto (ab+jactus) indica que sobre algo que está fora é "lançado" algum significado ou atributo. (Id., ibid, grifo do original).
}

Prosseguindo nessa concepção, o prefixo "ab" (de ab+jactus) equivale ao que se entende por "diante de", levando-nos a uma disposição, na qual o sujeito se posiciona frente ao objeto ou, de outra forma, equivale ao pesquisador diante da sua escolha de pesquisa. Uma paridade que seria padrão a todo método científico; o 
diferencial do processo estaria, pois, no talento individual de cada sujeito envolvido. Do exposto, constrói-se visualmente o seguinte design:

Figura 3 - Relação "sujeito-objeto" ou "pesquisador e fato pesquisado"

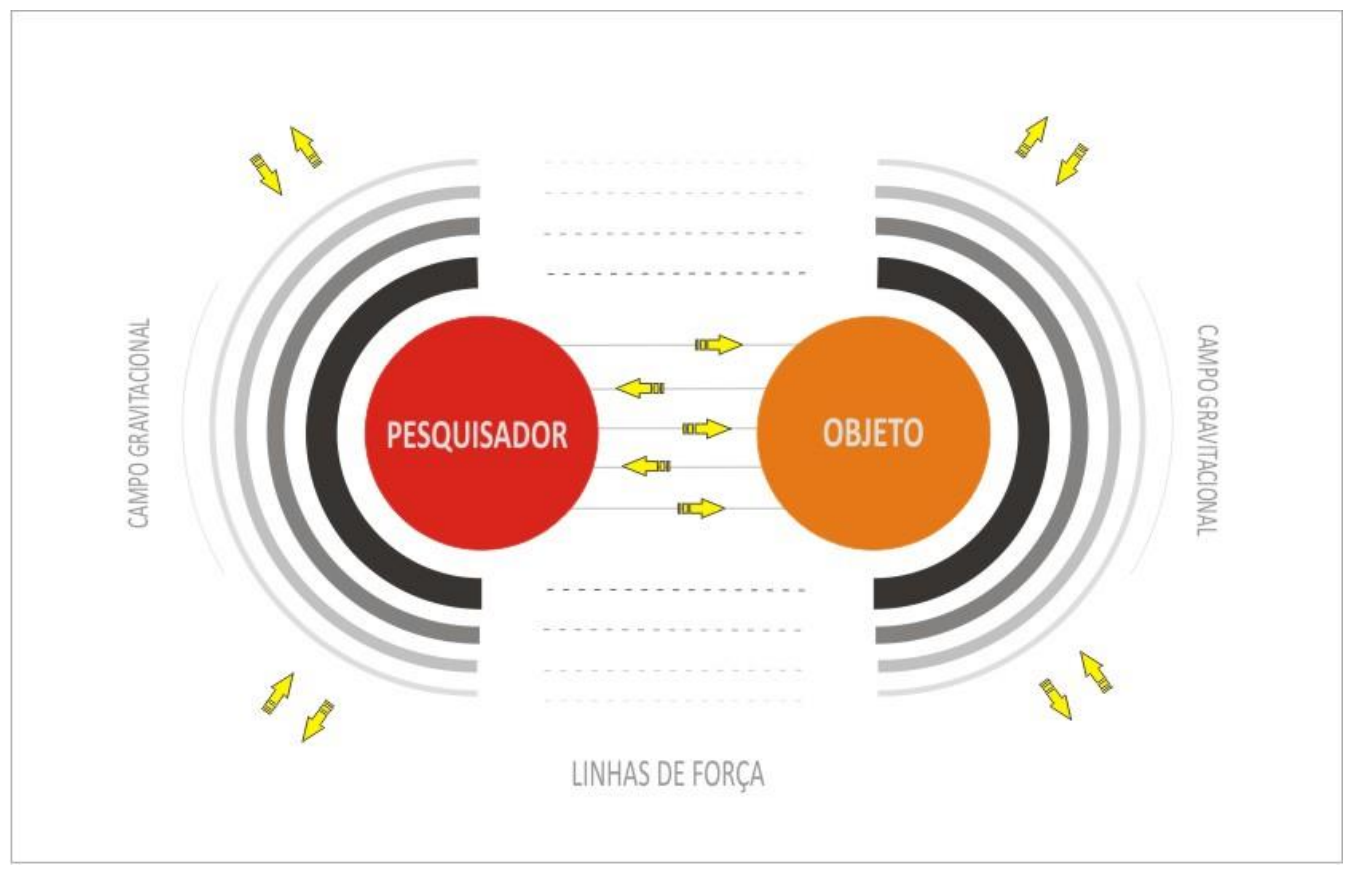

Fonte: Representação hipotética elaborada pela autora (2014/2015).

Se a Física afirma que corpos se atraem mutuamente, têm-se nesse esquema visual a representação hipotética, no caso em questão, do artista e sua obra em construção, com as devidas forças de atração e de repulsão. Isso significa que o referido princípio é decidido, tanto para o objeto, quanto para o pesquisador.

No processo, como um todo, há uma constante relação de trocas ou momento de formação deste e transformação daquele, isto é, durante o processo de pesquisa, ao mesmo tempo em que o objeto é construído, há, no pesquisador, uma abertura significativa de horizontes. Também é cabível se observar, conforme explicita Antônio Joaquim Severino (2007, p. 108) que "cada modalidade de conhecimento pressupõe um tipo de relação entre sujeito e objeto e, a depender dessa relação, temos conclusões diferentes".

Ao voltar à definição de "conhecimento" trazida por Santos Neto, afirma-se que é complementada pela existência de uma terceira vertente - o meio circundante. Em suas palavras, o autor subscreve: 
O conhecimento nasce, portanto, no momento em que o indivíduo percebe estar inserido em um ambiente, que há outros indivíduos e coisas junto a ele, e que parece haver ali um conjunto ou sistema a ser decifrado (SANTOS NETO, ibid., p. 23, grifo meu).

Nesta relação existencial entre homem e mundo, Maria Celeste Wanner, professora de Arte Contemporânea da Universidade Federal da Bahia, traz a seguinte colocação:

Existir é sentir a ação de fatos externos resistindo à nossa vontade, é estar numa relação, tomar um lugar na infinita miríade das determinações do universo, resistir e reagir, ocupar um tempo e espaços particulares (WANNER, 2010, p. 178, grifo meu).

Nesse caso, além do sujeito e do objeto, ver-se-á que "o meio" exerce importância de igual valor para a construção do conhecimento. Com essa verificação, conclui-se: o conhecimento é construído pela complementaridade entre um ser pensante, a coisa pensada e a realidade ou circunstância que os rodeiam. De outra forma, é nesta tríade entre "sujeito, objeto, meio" - na qual o tempo está para todos que a prática da pesquisa se constitui. Visualmente, elabora-se:

Figura 4 - Das três forças operantes na construção do conhecimento

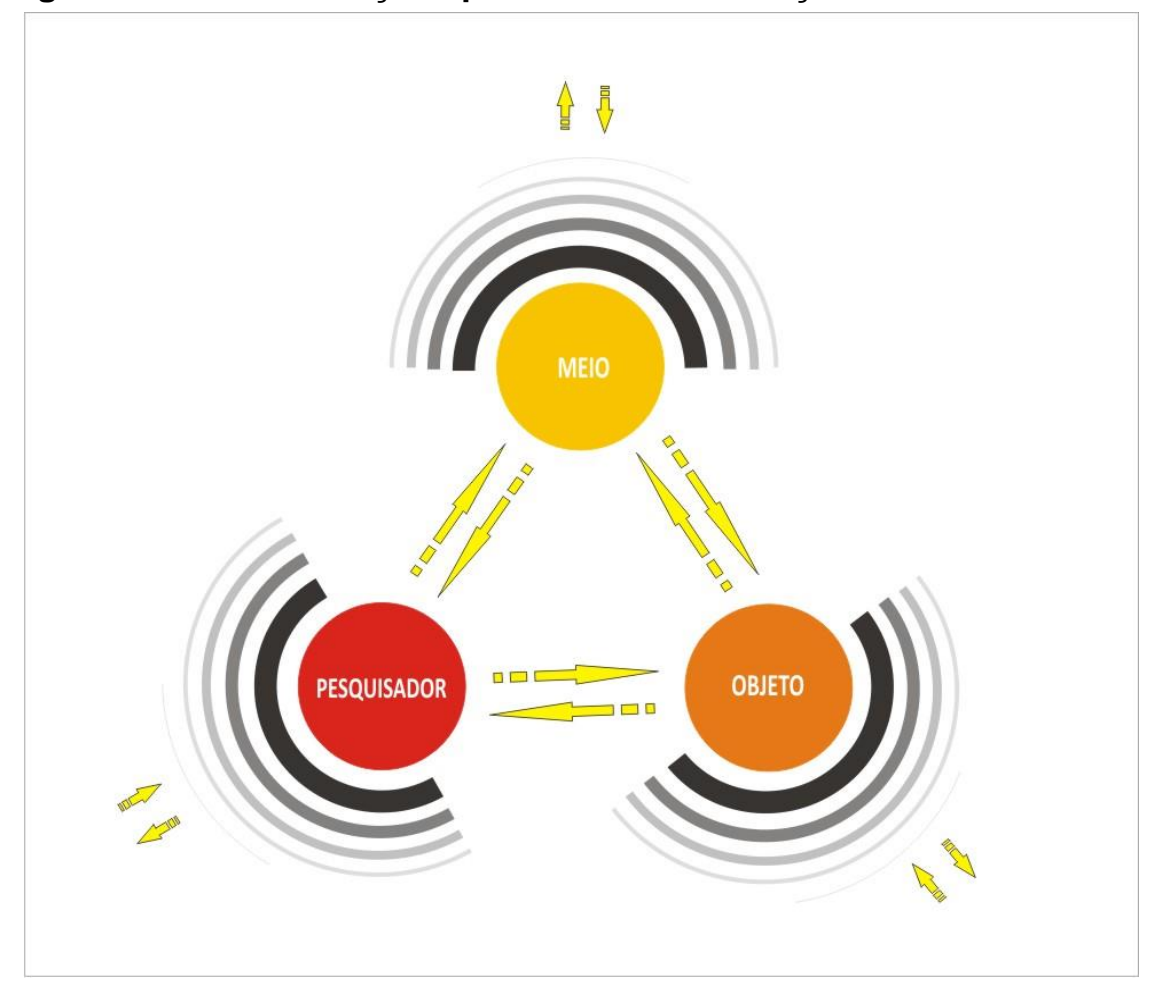

Fonte: Representação hipotética elaborada pela autora (2014/2015). 
$\mathrm{Na}$ configuração final não há, portanto, a presença de dois, mas de três elementos, os quais formam um triângulo, levando à instauração de um tripé metodológico voltado para a pesquisa universitária. A palavra tripé vem do grego tripous, que significa "três pés"; ao serem posicionados corretamente, gera estabilidade. Ao formular esse método, resolvo denominá-lo de "Método das Três Vertentes". Mas por quê?

"Vertente" deriva da expressão "Campo das Vertentes", termo que se configurou como conceito operacional do meu estudo (LADEIRA, 2015) como um todo, de modo a indicar a região espacial apreendida na pesquisa universitária. $\mathrm{O}$ "Método das Três Vertentes" seria, pois, um recorte do todo. Ambos se constituem por forças invisíveis, porém fervorosamente atuantes. Com essa questão ficam mais compreensíveis muitas teorias que embalam a arte, a exemplo do que tratam os franceses: Didi-Huberman (1953) com seus estudos sobre visualidade e visibilidade especialmente no livro "O que vemos, o que nos olha"; e os hábitos do pensamento exploradas por Maurice Merleau-Ponty (1908-1961), em "O visível e o invisível"; entre outros. Mas isso se tornam reflexões para outros momentos.

O conceito de força é algo intuitivo. Ainda que não vista, pode ser percebida, como a roupa que seca no varal, o som de uma música que entra pela janela ou o cheiro do almoço da vizinha que sentimos através do olfato. Lúcia Santaella menciona que: "não pode haver dúvidas de que o homem tem o insight natural das leis da natureza". Essas "leis de movimento operam por todo o universo, e a mente humana, a mente raciocinante é um produto dessas leis altamente onipresentes". (SANTAELLA, p. 104-106 apud WANNER, p. 49-50, 2010).

Assim, resta-nos "crer" nessa energia, pois conforme Santaella, agora se referindo ao pensamento de Peirce, "uma crença não nos coloca em ação prontamente, mas sim numa condição tal que devemos agir de certo modo quando a ocasião surgir”. (Id., ibid).

Temos, enfim, que transformar em matéria o que nossos sentidos nos mostram e, em textos, o que essa materialidade traz, uma vez que somos nós (artistas) os 
maiores intérpretes do que produzimos; somos nós - voltando a Danto - filósofos de nosso próprio fazer.

\section{Referências}

AITA, Virginia. Introdução e entrevista concedida por Arthur C. Danto a Virginia Aita (fevereiro de 2006). Disponível em: <http://www.forumpermanente.org/revista/edicao-0/entrevistas/arthur-danto> Acesso em: 4 dez. 2014.

DANTO, Arthur C. Crítica de arte após o fim da arte. Tradução de Miguel Gally et al. Revista de Estética e Semiotica, Brasília, v. 3, n. 1, p. 82-98 jan./jun. 2013.

DIDI-HUBERMAN, Georges. O que vemos, o que nos olha. São Paulo: Ed. 34, 2010 (2ª edição)

FEYNMAN, Richard P.; LEIGHTON, Robert B.; SANDS, Matthew. Feynman Lições de Física. v. I. Editora bookman, 2009.

LADEIRA, Marcillene. Reflexões metodológicas sobre processos de criação artística: relatos de experiência. In: XI Colóquio Franco brasileiro de Estética - Paris, Retina 8 e PPGAV/EBA/UFBA, out. 2014. Salvador, Bahia, 2014.

LADEIRA, Marcillene. Campo das Vertentes: uma coleta pictórica. 2015, 175 f. Dissertação. (Mestrado) Programa de Pós-Graduação em Artes Visuais da Universidade Federal da Bahia. Salvador, 2015.

MERLEAU-PONTY, Maurice. O visível e o invisível. São Paulo: Perspectiva, 2014.

PETRIN, Natália. Campo Gravitacional. Estudo Prático. Disponível em:< http://www.estudopratico.com.br/campo-gravitacional/. Acesso em: 5 dez. 2014.

PILLAR, Analice Dutra. Pesquisa em Artes Plásticas. Porto Alegre: Ed. UFRGS/ANPAP, 1993. p. 77-86.

SALLES. Cecília Almeida. Gesto Inacabado: processo de criação artística. SP: Annablume, 1998.

SALLES. Cecília Almeida. Redes de Criação: construção da obra de arte. SP: Horizonte, 2006.

SANTOS NETO, Isaias de Carvalho. Pesquisa: aventura entre métodos e mitos. Caderno do Programa de Pós-Graduação em Artes Visuais, EBA/UFBA. Salvador: EDUFBA, n. 2, 2004.

SEVERINO, Antônio Joaquim. Metodologia do trabalho científico. 23ª ed. São Paulo: Cortez, 2007.

VINICIUS, Marcelo. A filosofia da arte. Entrevista com Arthur Danto. Revista The Nation, publicação eletrônica, 18 de agosto de 2005. Novos estud. CEBRAP no.73. São Paulo, nov. 2005. Disponível em: <http://www.scielo.br/scielo.php?script=sci_arttext\&pid=S0101-33002005000300009 . Acesso em: 4 dez. 2017.

WANNER, Maria Celeste A. Paisagens Sígnicas. Salvador: EDUFBA, 2010.

TESSLER; Elida; BRITES, Blanca (Orgs.). O meio como ponto zero. Porto Alegre: Ed. UFRGS, 2002.

WILSON, S. Arte como Pesquisa. In: LEAO (Org.). O Chip e o caleidoscópio. São Paulo: Senac. 2005.

ZAMBONI, Silvio. A pesquisa em arte: um paralelo entre arte e ciência. 3. ed. Campinas, São Paulo: Autores Associados, 2006. 


\section{Marcilene Ladeira}

Mestra em Processos Criativos pelo Programa de Pós-Graduação em Artes Visuais, Escola de Belas Artes da Universidade Federal da Bahia - PPGAV/EBA/UFBA (com indicação, pela Banca Examinadora, a promoção antecipada e direta ao Doutorado). É integrante do Grupo MAMETO CNPq - Matéria, Memória e conceiTO em Poéticas Visuais Contemporâneas. Galeria representante: Luiz Fernando Landeiro Arte Contemporânea - Salvador/BA. Especialista em Docência do Ensino Superior pelo Instituto Pedagógico de Minas Gerais - IPEMIG; possui Graduação na área de Artes pelo Instituto de Artes e Design da Universidade Federal de Juiz de Fora - IAD/UFJF, com passagem inicial pela Escola de Belas da Universidade Federal do Rio de Janeiro - EBA/UFRJ. Atua em atelier desde 1996.

E-mail: marcillene.ladeira@gmail.com.br

Currículo: http://lattes.cnpq.br/6982176443396653

Recebido em 14 de julho de 2017 Aceito em 21 de novembro de 2017 